\title{
Grain refinement of AZ31 magnesium alloy by electromagnetic stirring under effect of grain-refiner
}

\author{
S Y GAO, Q C LE, Z Q ZHANG and J Z CUI* \\ Key Laboratory of Electromagnetic Processing of Materials, Ministry of Education, Northeastern University, \\ Shenyang 110819, China
}

MS received 3 April 2011; revised 12 June 2011

\begin{abstract}
The effects of electromagnetic stirring and $\mathrm{Al}_{4} \mathrm{C}_{3}$ grain refiner on the grain refinement of semicontinuously cast AZ31 magnesium alloy were discussed in this investigation. The results indicate that electromagnetic stirring has an effective refining effect on the grain size of $\mathrm{AZ31}$ magnesium alloy under the effect of $\mathrm{Al}_{4} \mathrm{C}_{3}$ grain refiner. Electromagnetic stirring can 'activate' the $\mathrm{Al}_{4} \mathrm{C}_{3}$ particles, resulting in more heterogeneous nucleation sites for the primary $\alpha$-Mg grains. But, longer holding time can 'deactivate' the $\mathrm{Al}_{4} \mathrm{C}_{3}$ particles and poison the grain refining effect.
\end{abstract}

Keywords. Low-frequency electromagnetic field; AZ31 magnesium alloy; $\mathrm{Al}_{4} \mathrm{C}_{3}$; grain refinement.

\section{Introduction}

AZ31 alloy is the most widely used wrought magnesium alloy, but its plastic deformation properties are relatively poor due to its hexagonal close-packed ( $h c p)$ crystal structure. Grain refinement is one of the most effective methods to improve the mechanical properties of magnesium alloys (Lahaie and Bouchard 2001; Yang et al 2008). The finer grain size reduces the size of defects and second-phase particles such as $\beta-\mathrm{Mg}_{17} \mathrm{Al}_{12}$ (Watanabe et al 2000), producing improved mechanical properties. Meanwhile, grain refinement of AZ31 magnesium alloy is extremely effective in improving its formability at room temperature (Watanabe et al 2000; Yang et al 2008). A variety of methods such as superheating, carbon inoculation, addition of solute elements and electromagnetic stirring (Tamura et al 1998; Mukai et al 2000) have been reported to refine AZ31 magnesium alloy.

Among these methods, carbon inoculation is known to be the most effective for operating at a low temperature and less fading with long-time holding (Yang et al 2008; Lahaie and Bouchard 2001), and it is the most common grain refinement method for Mg-Al based alloys (Tamura et al 1998; Liu et al 2009). Carbon-containing agents, such as $\mathrm{Al}_{4} \mathrm{C}_{3}$ can act as nucleating agents (Yano et al 2003; Lu et al 2005). The addition of $\mathrm{Al}_{4} \mathrm{C}_{3}$ particles form a large number of dispersed sites for heterogeneous nucleation, and therefore, enhances the nucleation rate.

Both $\mathrm{Al}_{4} \mathrm{C}_{3}$ and $\alpha$-Mg possess hexagonal crystal structures, and they have similar lattice parameters $(a=$ $0.32088 \mathrm{~nm}, c=0.52017 \mathrm{~nm}$ for $\alpha-\mathrm{Mg} ; a=0.33388 \mathrm{~nm}$, $c=0.49900 \mathrm{~nm}$ for $\mathrm{Al}_{4} \mathrm{C}_{3}$ ). According to Bramfit (1970), the most effective condition for heterogeneous nucleation is

\footnotetext{
*Author for correspondence (jzcui@mail.neu.edu.cn)
}

that the lattice disregistry between grain refiner crystal and a substrate $\delta$ should be less than $6 \%$. Based on the Bramfit (1970) two-dimensional lattice misfit theory, the obtained disregistry value of $(10 \overline{1} 0)_{\mathrm{Mg}} / /(10 \overline{1} 0)_{\mathrm{Al}_{4} \mathrm{C}_{3}}$ is $3 \cdot 35 \%$. So, $\mathrm{Al}_{4} \mathrm{C}_{3}$ particles can act as heterogeneous nucleus for $\alpha-\mathrm{Mg}$ crystals.

The electromagnetic stirring process is receiving increasing attention due to its effectiveness in grain refinement, easy operation, elimination of macrosegregation, improved temperature distribution during solidification, and enhanced casting velocity (Xiao et al 1998; Komarov et al 2005; Gao et al 2010a). The electromagnetic stirring process is based on the interaction between the alloy melt and the electromagnetic field, and the interaction can cause vibration and convection in the melt, promoting the nucleation and the formation of equiaxed grains (Gao et al 2010b).

To our knowledge, there are no reports that discuss the effects and especially the refining mechanism of grain refiner and low-frequency electromagnetic field on the grain refinement of AZ31 magnesium alloy during semi-continuous casting. In the present investigation, effects of $\mathrm{Al}_{4} \mathrm{C}_{3}$ refiner and electromagnetic fields on grain refinement of the ascast AZ31 magnesium alloy during the solidification process are discussed; furthermore, effect of holding time on the refinement of AZ31 magnesium alloy was investigated.

\section{Experimental}

$\mathrm{Al}_{4} \mathrm{C}_{3}$ grain refiner was synthesized by powder metallurgy. The raw materials included aluminum powder $(99.8 \%$ pure, $50 \mu \mathrm{m}$ in diameter), graphite powder $(99.6 \%$ pure, $50 \mu \mathrm{m}$ in diameter), and a mixture of $\mathrm{MgCO}_{3}$ and $\mathrm{CaCO}_{3}$ powder (99.5\% pure, $50 \mu \mathrm{m}$ in diameter). AZ31 magnesium alloy 


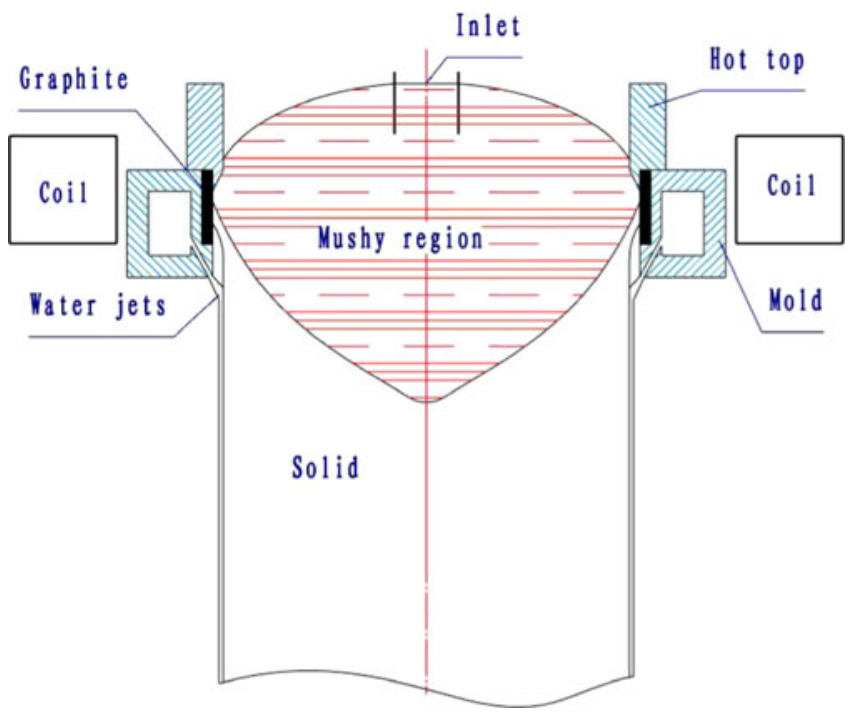

Figure 1. Schematic diagram of semi-continuous cast equipment.

was used as the alloy to refine and its chemical composition was: Al, 3.0-4.0\%; Zn, 0.8-1.1\%; Mn, 0.15-0.5\%; Fe, $0.005 \%$; $\mathrm{Mg}$, balance. The AZ31 alloy was melted in a crucible resistance furnace under a protective cover gas mixture of $\mathrm{SF}_{6}$ and $\mathrm{CO}_{2} . \mathrm{Al}_{4} \mathrm{C}_{3}$ grain refiner was added into the melt at $680{ }^{\circ} \mathrm{C}$ with and without electromagnetic stirring ( $I=120 \mathrm{~A}, f=30 \mathrm{~Hz}$ ) to study its effect on grain refinement. After holding for 60 and $90 \mathrm{~min}$, respectively the melts were semi-continuously cast with an ingot size of $\Phi 165 \times$ $600 \mathrm{~mm}$. A schematic diagram of the semi-continuous casting equipment is shown in figure 1. Grain refinement of AZ31 alloy was investigated at the edge, 1/2 radius, and the central part of the ingots. The AZ31 alloys were etched with a solution of $3.0 \mathrm{~g}$ picric, $50 \mathrm{ml}$ alcohol, distilled water, $5 \mathrm{ml}$ and acetic acid, $2.5 \mathrm{ml}$ and then were examined using OLYMPUS SZX16 optical microscope to investigate the microstructure. The grain size analysis was carried out by the standard linear intercept method using Imagetool software. The samples were also observed using a scanning electron microscope (SEM) for morphological characterization.

\section{Results and discussion}

Figure 2 shows optical micrographs of the as-cast AZ31 magnesium alloys, and the corresponding average grain sizes for different samples are shown in figure 3. Figures 2(a), (b), and (c) show the edge, 1/2 radius and central structures, respectively of the alloy with effect of $\mathrm{Al}_{4} \mathrm{C}_{3}$ grain refiner after a holding time of $60 \mathrm{~min}$ at $680^{\circ} \mathrm{C}$. Figures 2(d), (e) and (f) show the edge, $1 / 2$ radius and central structures, respectively of the alloy with combined effects of $\mathrm{Al}_{4} \mathrm{C}_{3}$ grain refiner and low-frequency electromagnetic stirring after a holding time of $60 \mathrm{~min}$ at $680^{\circ} \mathrm{C}$.

Clearly, the grain size decreases significantly when low-frequency electromagnetic stirring is employed. Since employment of electromagnetic stirring is the only process performed on the samples shown in figures 2(a), (b), and (c), it is believed that the low-frequency electromagnetic stirring process is responsible for the grain refining effect observed in figures $2(\mathrm{~d})$, (e), and (f). $\mathrm{Al}_{4} \mathrm{C}_{3}$ has a relatively high melting point and high thermal stability (Gao et al 2010a, b, c), and it can act as a heterogeneous nucleus for $\alpha$-Mg crystals, leading to refined and uniform grains. For the sample only under the effect of grain refiner, figure 3 shows that the average grain size for the edge (figure 2(a)) of the ingot is $490 \mu \mathrm{m}$; the grain size for the $1 / 2$ radius (figure $2(\mathrm{~b})$ ) is $470 \mu \mathrm{m}$, and the grain size for the central structures (figure 2(c)), it is $430 \mu \mathrm{m}$. With the combined effects of grain refiner and electromagnetic stirring, it can be seen from figure 3 that the average grain size for the alloy is finer than that for the sample without the effect of electromagnetic stirring. The average grain size for the edge (figure 2(d)) of the ingot is $270 \mu \mathrm{m}$; the grain size for the $1 / 2$ radius (figure $2(\mathrm{e})$ ), it is $280 \mu \mathrm{m}$, and the grain size for the central structures (figure 2(f)), it is $290 \mu \mathrm{m}$. The average grain size from the edge to the central structures of the ingot increases, but the difference is very small and the refining effect is predominant and stable.

Figures 2(g), (h) and (i) show the edge, 1/2 radius and central structures, respectively of the sample under the combined effects of $\mathrm{Al}_{4} \mathrm{C}_{3}$ grain refiner and low-frequency electromagnetic stirring after a holding time of $90 \mathrm{~min}$ at $680^{\circ} \mathrm{C}$, and the corresponding grain sizes, as indicated in figure 3 , are $350 \mu \mathrm{m}, 360 \mu \mathrm{m}$, and $300 \mu \mathrm{m}$. Clearly, grain size of the alloy increases with increasing holding time of the melt.

Figure 4 shows SEM results of the AZ31 magnesium alloy with the combined effects of $\mathrm{Al}_{4} \mathrm{C}_{3}$ grain refiner and electromagnetic stirring after $60 \mathrm{~min}$ holding time at $680^{\circ} \mathrm{C}$. Figure 4(d) shows EDS spectra of the particle as indicated in figure $4(\mathrm{~b})$, and the particle is identified as $\mathrm{Al}_{4} \mathrm{C}_{3}$ grain refiner. The $\mathrm{Mg}$ peak in figure $4(\mathrm{~d})$ is believed to be contributed by the matrix. Therefore, it appears that this particle mainly consists of $\mathrm{Al}, \mathrm{C}$ and $\mathrm{O}$. Since the oxygen potential in the melt is dictated by $\mathrm{Mg}$ and is expected to be extremely low (Gaskell 1995), it is thermodynamically impossible to form $\mathrm{Al}-\mathrm{C}-\mathrm{O}$ compounds in the melt. Therefore, it is believed that these particles are originally $\mathrm{Al}_{4} \mathrm{C}_{3}$ particles, and the oxygen is introduced during sample preparation as a result of the following reaction (Lu et al 2005).

$$
\mathrm{Al}_{4} \mathrm{C}_{3}(s)+12 \mathrm{H}_{2} \mathrm{O}(l)=4 \mathrm{Al}(\mathrm{OH})_{3}(s)+3 \mathrm{CH}_{4}(g) .
$$

\subsection{Effect of $\mathrm{Al}_{4} \mathrm{C}_{3}$ on grain refinement of $A Z 31$ magnesium alloy}

It is widely appreciated that the microstructure of a casting can be refined by increasing the number of potent nuclei in the melt and the thermal and constitutional undercooling at the advancing $S / L$ interface (Maxwell and Hellawell 1975; Easton and St John 2001). The binding energy in $\mathrm{Al}_{4} \mathrm{C}_{3}$ is lower than that of $\alpha-\mathrm{Mg}$ ( $\mathrm{Lu}$ et al 2005). It is well known that the binding energy of a particle can affect its thermal stability. Lower binding energy can result in higher thermal 



Figure 2. Optical micrographs of as-cast AZ31 alloy. (a), (b) and (c) show edge, 1/2 radius and central structures, respectively of alloy with effect of $\mathrm{Al}_{4} \mathrm{C}_{3}$ grain refiner after a holding time of $60 \mathrm{~min}$ at $680^{\circ} \mathrm{C}$. (d), (e) and (f) show edge, $1 / 2$ radius and central structures, respectively of alloy with combined effects of $\mathrm{Al}_{4} \mathrm{C}_{3}$ grain refiner and electromagnetic stirring after a holding time of $60 \mathrm{~min}$ at $680{ }^{\circ} \mathrm{C}$ and (g), (h) and (i) show edge, 1/2 radius and central structures, respectively of alloy after a holding time of $90 \mathrm{~min}$ at $680^{\circ} \mathrm{C}$.

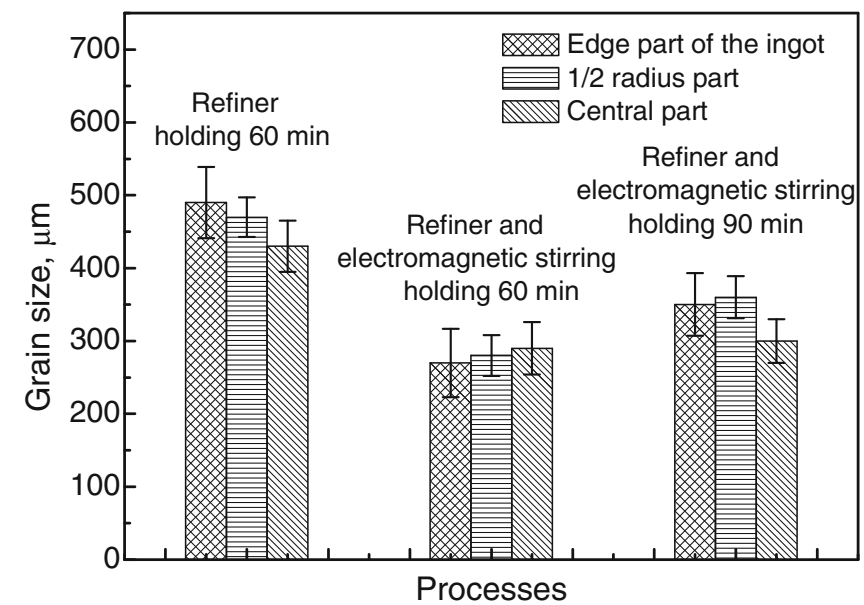

Figure 3. Grain sizes of AZ31 magnesium alloy samples by different processes.

stability of the system (Bramfit 1970). The $\mathrm{Al}_{4} \mathrm{C}_{3}$ is thermally stable up to a temperature of about $2200^{\circ} \mathrm{C}$ ( Lu et al 2005), and therefore, addition of $\mathrm{Al}_{4} \mathrm{C}_{3}$ will not introduce any solute into the melt to facilitate a strong constitutional undercooling required for the grain refining effect. The lower binding energy of $\mathrm{Al}_{4} \mathrm{C}_{3}$ than that of $\alpha-\mathrm{Mg}$ indicates better thermal stability of $\mathrm{Al}_{4} \mathrm{C}_{3}$ in the molten magnesium alloy at high temperature. Therefore, it is reasonable to suggest that $\mathrm{Al}_{4} \mathrm{C}_{3}$ itself is a potent nucleating site for primary $\alpha-\mathrm{Mg}$, and the addition of $\mathrm{Al}_{4} \mathrm{C}_{3}$ into the melt will increase the nucleation rate (Easton et al 2006; Lu et al 2006). The primary $\alpha-\mathrm{Mg}$ grains are nucleated on the potent nucleating site of $\mathrm{Al}_{4} \mathrm{C}_{3}$ in the melt, and grow radially in a uniform fashion. So, $\mathrm{Al}_{4} \mathrm{C}_{3}$ particles are expected to act as the potent nucleating sites for $\alpha-\mathrm{Mg}$ grains, contributing to the AZ31 alloy grain size decreasing from millimeters to about $430 \mu \mathrm{m}$.

\subsection{Effect of electromagnetic stirring on grain refinement of AZ31 magnesium alloy}

Since employment of electromagnetic stirring is the only process performed after the samples shown in figures 2(a), (b), and (c), it is believed that the low-frequency electromagnetic stirring process is responsible for the grain refining effect observed in figures 2(d), (e), and (f). The electromagnetic 

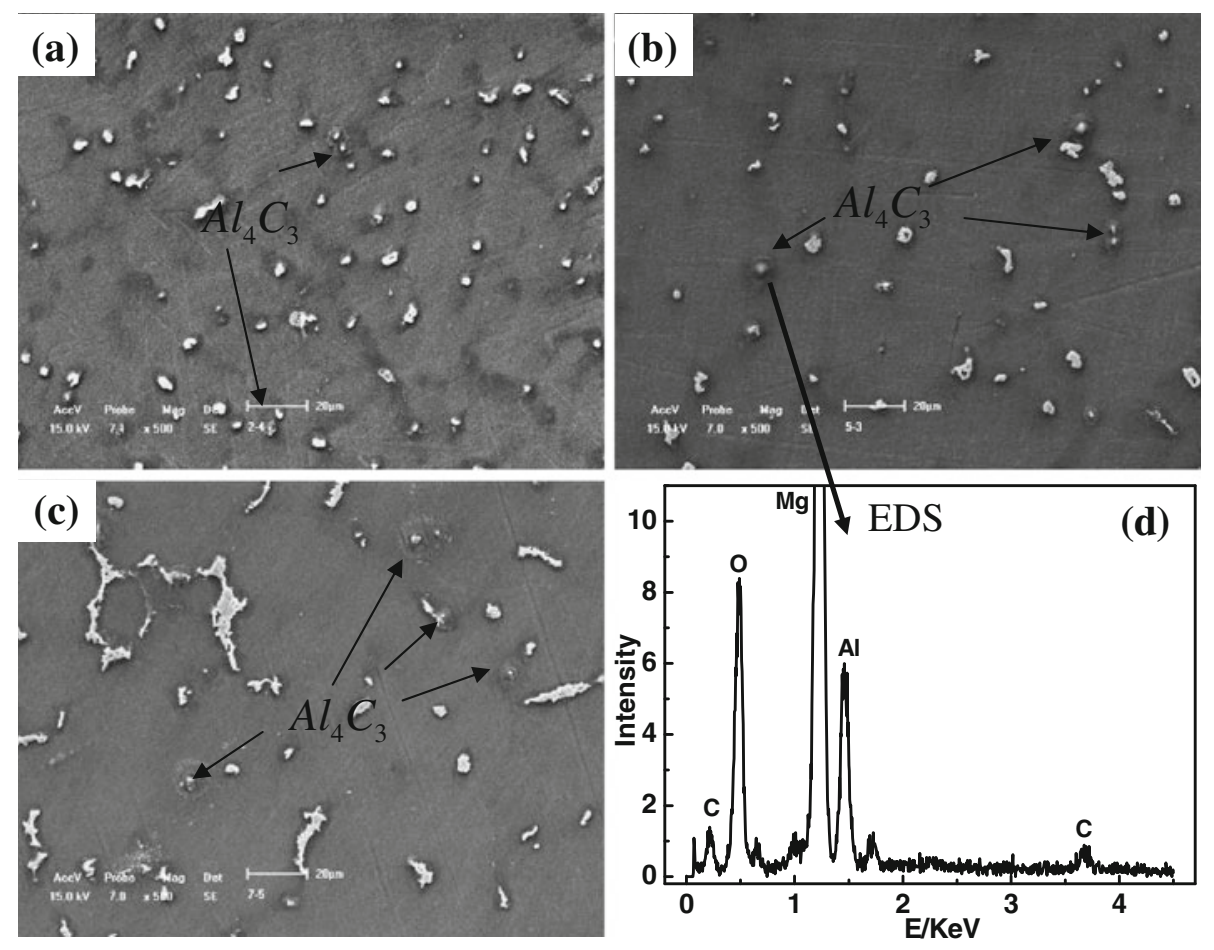

Figure 4. SEM images of as-cast $\mathrm{AZ} 31$ alloy under combined effects of electromagnetic field and $\mathrm{Al}_{4} \mathrm{C}_{3}$ grain refiner after a holding time of $60 \mathrm{~min}$ at $680^{\circ} \mathrm{C}$. (a), (b) and (c) show edge, $1 / 2$ radius and central structures, respectively, (d) EDS spectra of particle as indicated in figure $4(\mathbf{b})$.

stirring process introduces forced convection in the AZ31 alloy melt, enhancing the heat exchange between the melt and mold. Meanwhile, the scouring effect caused by forced convection and the Joule heat generated by the current can break, crush or fuse the dendrite arms during solidification. The broken dendrite can also act as a nucleation site for new fine grains, improving the nucleation rate.

\subsection{Refinement mechanism of electromagnetic stirring and grain refiner}

According to the solidification principles (Xiao et al 1998; Gao et al 2010c), the latter formed solidification region has more refined grains due to the formation of more nucleating sites. The edge part of the ingot was preferentially solidified, and the grain size is large due to fewer $\mathrm{Al}_{4} \mathrm{C}_{3}$ particles. With the progress of the solidification process, some $\mathrm{Al}_{4} \mathrm{C}_{3}$ particles move from the edge to the $1 / 2$ radius part. So, there are more nucleating sites in this area than that at the edge part, and more potent nucleating sites result in finer grain sizes at the $1 / 2$ radius, as indicated in figures 2 and 3 . The central part of the ingot is the final solidification area, and in this area there are many active nucleating sites, $\mathrm{Al}_{4} \mathrm{C}_{3}$ particles. So, the central part of the ingot has the finest grain size.

With the presence of $\mathrm{Al}_{4} \mathrm{C}_{3}$ grain refiner particles, electromagnetic stirring can make the particles more uniformly distributed throughout the melt, improving the heterogeneous nucleation of $\alpha$-Mg grains. In addition, the strong convection caused by electromagnetic stirring can 'activate' the $\mathrm{Al}_{4} \mathrm{C}_{3}$ grain refiner particles. Moreover, strong convection has cleaning effect on the grain refiner particles and can make the surface energy increase, thus enhancing the possibility for the combination of $\mathrm{Mg}$ atoms and $\mathrm{Al}_{4} \mathrm{C}_{3}$ particles, improving the nucleating efficiency. So, with the presence of $\mathrm{Al}_{4} \mathrm{C}_{3}$ grain refiner particles, the electromagnetic stirring process can produce very effective refinement effect on the grain size of AZ31 alloy, as indicated in figures 2 and 3.

\subsection{Effect of holding time on grain refinement of AZ31 magnesium alloy}

Figures 2(d), (e), and (f) and figures 2(h), (i), and (g) compare the optical micrographs of a sample treated at $680^{\circ} \mathrm{C}$ with combined effects of $\mathrm{Al}_{4} \mathrm{C}_{3}$ grain refiner and low-frequency electromagnetic stirring after holding times of $60 \mathrm{~min}$ and $90 \mathrm{~min}$. The obtained average grain size is shown in figure 3 . As can be seen from figures 2 and 3, grain size for the sample after 60 min holding time is finer than that after $90 \mathrm{~min}$ holding time. This is because longer holding times can make the $\mathrm{Al}_{4} \mathrm{C}_{3}$ particles agglomerate and settle, deteriorating the refining effect. Therefore, longer holding times can 'deactivate' the $\mathrm{Al}_{4} \mathrm{C}_{3}$ grain refiner particles, leading to a decreased possibility for $\mathrm{Mg}$ atoms to nucleate on the $\mathrm{Al}_{4} \mathrm{C}_{3}$ particles. So, in this situation the $\mathrm{Al}_{4} \mathrm{C}_{3}$ particles cannot act as potent nucleating sites for $\alpha$-Mg grains. 


\section{Conclusions}

Grain refinement of AZ31 magnesium alloy by electromagnetic stirring under the effect of $\mathrm{Al}_{4} \mathrm{C}_{3}$ grain-refiner has been investigated and it was found that, with the presence of $\mathrm{Al}_{4} \mathrm{C}_{3}$ grain-refiner particles, electromagnetic stirring has a significant effect on the grain refinement of AZ31 magnesium alloy. Electromagnetic stirring can 'activate' the $\mathrm{Al}_{4} \mathrm{C}_{3}$ particles, contributing to improved heterogeneous nucleation for the primary $\alpha$-Mg grains. Longer holding time can 'deactivate' the $\mathrm{Al}_{4} \mathrm{C}_{3}$ particles, and poison the grain refining effect.

\section{References}

Bramfit B L 1970 Metall. Mater. Trans. A1 1987

Easton M A and St John D H 2001 Acta Mater. 491867

Easton M A, Schiffl A and Yao J Y 2006 Scr. Mater. 55379

Gao S Y, Cui J Z, Le Q Z and Zhang Z Q 2010a Materialwissenschaft und Werkstofftechnik 41652

Gao S Y, Le Q Z, Cui J Z and Zhang Z Q 2010b Chin. J. Mater. Res. 24597
Gao S Y, Le Q Z, Zhang Z Q and Cui J Z 2010c Acta Metall. Sin. 461495

Gaskell D R 1995 Introduction to the thermodynamics of materials (Washington, DC: Taylor \& Francis) p. 370

Komarov S V, Kuwabara M and Abramov O V 2005 ISI J. Inter. 451765

Lahaie D J and Bouchard M 2001 Metall. Mater. Trans. B32 697

Liu S F, Zhang Y, Han H and Li B 2009 J. Alloys Compd 487202

Lu L, Dahle A K and St John D H 2005 Scr. Mater. 53517

Lu L, Dahle A K and St John D H 2006 Scr. Mater. 542197

Maxwell I and Hellawell A 1975 Acta Metall. 23229

Mukai T, Watanabe H and Higashi K 2000 Mater. Sci. Forum. 350/351 159

Tamura Y, Kono N and Motegi T 1998 J. Jpn Inst. Ligh. Met. 48185

Watanabe H, Tsutsui H and Mukai T 2000 Mater. Sci. Forum. 350/351 171

Xiao S X, Wang C Y and Chen T L 1998 The application of the discrete variational method in the density functional theory to chemistry and materials physics (Beijing: Science Press) p. 92

Yang M B, Pan F S, Cheng R J and Tang A T 2008 J. Alloys Compd 461298

Yano E, Tamura Y, Motegi T and Sato E 2003 Mater. Trans. 44107 